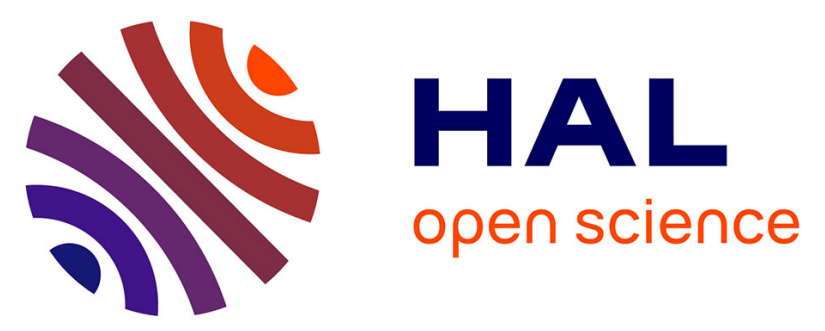

\title{
Exploring the Role of Information Systems in Mitigating Gate Congestion Using Simulation: Theory and Practice at a Bulk Export Terminal Gate
}

Mihai Neagoe, Mohammad Sadegh Taskhiri, Hong-Oanh Nguyen, Paul Turner

\section{- To cite this version:}

Mihai Neagoe, Mohammad Sadegh Taskhiri, Hong-Oanh Nguyen, Paul Turner. Exploring the Role of Information Systems in Mitigating Gate Congestion Using Simulation: Theory and Practice at a Bulk Export Terminal Gate. IFIP International Conference on Advances in Production Management Systems (APMS), Aug 2018, Seoul, South Korea. pp.367-374, 10.1007/978-3-319-99704-9_45 . hal02164888

\section{HAL Id: hal-02164888 \\ https://hal.inria.fr/hal-02164888}

Submitted on 25 Jun 2019

HAL is a multi-disciplinary open access archive for the deposit and dissemination of scientific research documents, whether they are published or not. The documents may come from teaching and research institutions in France or abroad, or from public or private research centers.
L'archive ouverte pluridisciplinaire HAL, est destinée au dépôt et à la diffusion de documents scientifiques de niveau recherche, publiés ou non, émanant des établissements d'enseignement et de recherche français ou étrangers, des laboratoires publics ou privés.

\section{(c)(1)}

Distributed under a Creative Commons Attribution| 4.0 International License 


\title{
Exploring the role of information systems in mitigating gate congestion using simulation: Theory and Practice at a bulk export terminal gate
}

\author{
Mihai Neagoe ${ }^{1(\bowtie)[0000-0003-4362-8132]}$, Mohammad Sadegh Taskhiri1[0000-0002-9871-361X], \\ Hong-Oanh Nguyen ${ }^{20000-0002-9167-0143]}$ and Paul Turner ${ }^{10000-0003-4504-2338]}$ \\ ${ }^{1}$ ARC Centre for Forest Value, Discipline of ICT, College of Sciences and Engineering, Uni- \\ versity of Tasmania, Hobart, Australia \\ ${ }^{2}$ Australian Maritime College, College of Sciences and Engineering, University of Tasmania, \\ Hobart, Australia \\ Mihai.Neagoedutas.edu.au
}

\begin{abstract}
Using an Australian wood chip export terminal as a case study, this research presents a terminal gate simulation model that improves understanding of the complex interactions at the terminal gate and describes the potential of information and digital systems alternatives for mitigating congestion. The alternatives modelled include: a terminal appointment system to schedule truck arrivals; integrating weigh-bridge information to eliminate one stage of the unloading process; and, reducing conveyor operation time.

Simulation results indicate that a terminal appointment system can reduce turnaround times by up to $23 \%$, primarily through a reduction in waiting times. Integrating weigh-bridge information can improve turnaround by up to $18 \%$, while reducing the conveyor operation time can improve turnaround by up to $5 \%$. The paper highlights that achieving these simulated results in practice actually relies on a range of factors and assumptions hard to embed in the simulation. These factors influence the nature of the complex interactions at the terminal gate and include the extent to which stakeholders are willing to share information and develop or retain levels of trust between each other.

The paper argues that one potentially effective strategy for aligning stakeholders' interests involves engaging them all in the decision-making processes in finding and developing a suitable congestion management solution. This approach mitigates concerns regarding system abuse, ensures all technological and business requirements of stakeholders are considered and, enhances the implementation process to deliver increased effectiveness of the solution.

This research is part of on-going Australian Research Council funding through the Industrial Transformation Research Program.
\end{abstract}

Keywords: Information Sharing, Discrete Event Simulation, Land Interface, Willingness, Trust. 


\section{Introduction}

Between 2012 and 2015, exports from Australian wood chip port terminals increased by more than $40 \%$ to 10.1 million tons per year [17]. Based on recent port authorities' annual reports, this upward trend has continued in 2016 and 2017. This volume surge has been a major contributing factor to growing port terminal congestion, especially in land-side delivery operations. Wood chip supply chains involve sales of a high-volume, low-margin, price sensitive commodity product. The profitability of the chain can be adversely impacted by port terminal congestion. These impacts affect stakeholders along the entire wood chip supply chain. Surprisingly, there has been limited analysis of alternative approaches to addressing terminal congestion particularly with regard to this type of bulk port terminal.

This research presents a terminal gate simulation model that improves understanding of the complex interactions at the terminal gate and describes the potential for information and digital system alternatives to mitigate congestion. The paper highlights that achieving these simulated results in practice actually relies on a range of factors and assumptions hard to embed in the simulation. These factors influence the nature of the complex interactions at the terminal gate and include the extent to which stakeholders are willing to share information and develop or retain levels of trust between one another.

Information Systems and Terminal Gate Congestion Management. Land-side throughput at port terminal gates is directly impacted by the number, operating hours and productivity of each gate [14]. Approaches to managing gate congestion can be divided into two categories: (i) Gate availability management, (ii) Gate operational management. Gate availability may be increased by extending the gate working hours $[1,9]$ supported by gate automation technologies utilising Radio-frequency Identification (RFID) and Optical Character Recognition (OCR) [14] for land-side transporters and other port users.

Gate operational management may be improved by terminal appointment systems (TAS) [7, 12], vessel dependent time windows (VDTW) [4], and peak hour pricing or incentive programs [10]. TAS schedule truckers' arrivals at the terminal to deliver and pick-up cargoes at specified time intervals. Analytical approaches such as programming [20], queuing theory [4] and simulation [11] explored the potential impact of TAS and have typically found that significant reductions in truck turnaround and waiting times can be achieved. However, empirical investigations following implementation of TAS have reported mixed results due to a range of factors, including incompatibility between system requirements and business [9], manipulation by opportunistic users [15] and use of congestion management systems as revenue alternatives [7]. Terminal gate congestion management has received significantly more attention in the context of containerized goods. Given the similarities between container and bulk terminal operations [3] we consider insights gained in container terminals to have similar relevance in the context of bulk operations. 
This paper argues that aligning stakeholders' interests involves engaging them all in the decision processes around finding and developing a suitable congestion management solution. This approach should mitigate concerns regarding system abuse, capture and align technological and business requirements of stakeholders and enhance the implementation process to positively impact solution effectiveness.

\section{Methodology}

\subsection{Field-Site: Wood Chip Terminal and Land-Side Operations}

The bulk wood chip export terminal used for the simulation modelling in this project operates in a medium-size port in Australia. Wood chips are delivered to the terminal from three processing facilities by a dedicated fleet of trucks and are stored at the terminal in preparation for vessel arrivals. Sufficient product has to be available to complete the loading at the time of vessel arrival since the vessel hourly loading rate costs are far greater than those of truck unloading. The truck delivery cycle average, depending on the distance from the facilities, can be 40,90 or 300 minutes for a round-trip, excluding terminal unloading.

At the terminal, trucks are weighed before and after unloading on a weighbridge. Operators swipe an RFID card that records arrival and departure time, gross and net truck weight and the product delivered. Trucks can be unloaded by two hydraulic ramps. Product falls into a common collector bin and is moved to stockpiles using by conveyor belt.

On average trucks wait to unload between 7-10 minutes. However, close to $30 \%$ of the trucks wait between 15 and 45 minutes to unload. In the context of relatively short delivery cycles, excessive waiting times can lead to substantial truck productivity losses. Terminal visits and discussions with staff also confirmed the terminal was regularly experiencing significant truck congestion at the terminal gate and unloading ramps.

\subsection{Discrete Event Simulation Model of Terminal Gate Operations}

A simulation approach allows for representation of some of the complex interactions taking place at a terminal [11] and insights into operations that may support the development of tangible solutions for industry [8]. Simulation also allows a 'what-if' analysis under certain scenarios and comparison between multiple alternatives [6]. This research deployed a discrete event simulation model to represent terminal gate operations.

The literature on dry bulk terminal distinguishes between export terminals, and import terminals [18] as they and generally serve only one of the two functions. Researchers have primarily focused on ores as the primary dry bulk commodities of interest: coal export [19], coal and iron import [3] and bauxite imports [5]. Munisamy [16] is one of the few examples of a timber terminal related research. One of the main problems explored in the dry bulk terminal literature is how to increase the capacity of dry bulk terminals $[5,19]$ with the aim of reducing vessel waiting times and associated penalties. Throughput capacity increases on the maritime side are not always met with a similar 
approach on the land side. Financial penalties for vessel waiting times (demurrage) are one of the most frequently mentioned reasons for optimizing and improving the loading or unloading process at terminals.

Terminal arrival and departure data were collected from reports generated by the weigh-bridge. Three months of truck arrivals were included, totaling more than 15,000 trips. The duration of individual unloading stages was determined using geo-fences implemented in a commercial navigation software which used inputs from on-board GPS data from one trucking operator. The data collected were then fitted to distributions, using the Arena Input Analyzer, so they could be sampled during the simulation using a Monte Carlo sampling technique. The simulation model logic follows closely the process flow at the terminal and is illustrated in Figure 1 and includes the alternatives modelled to address congestion.

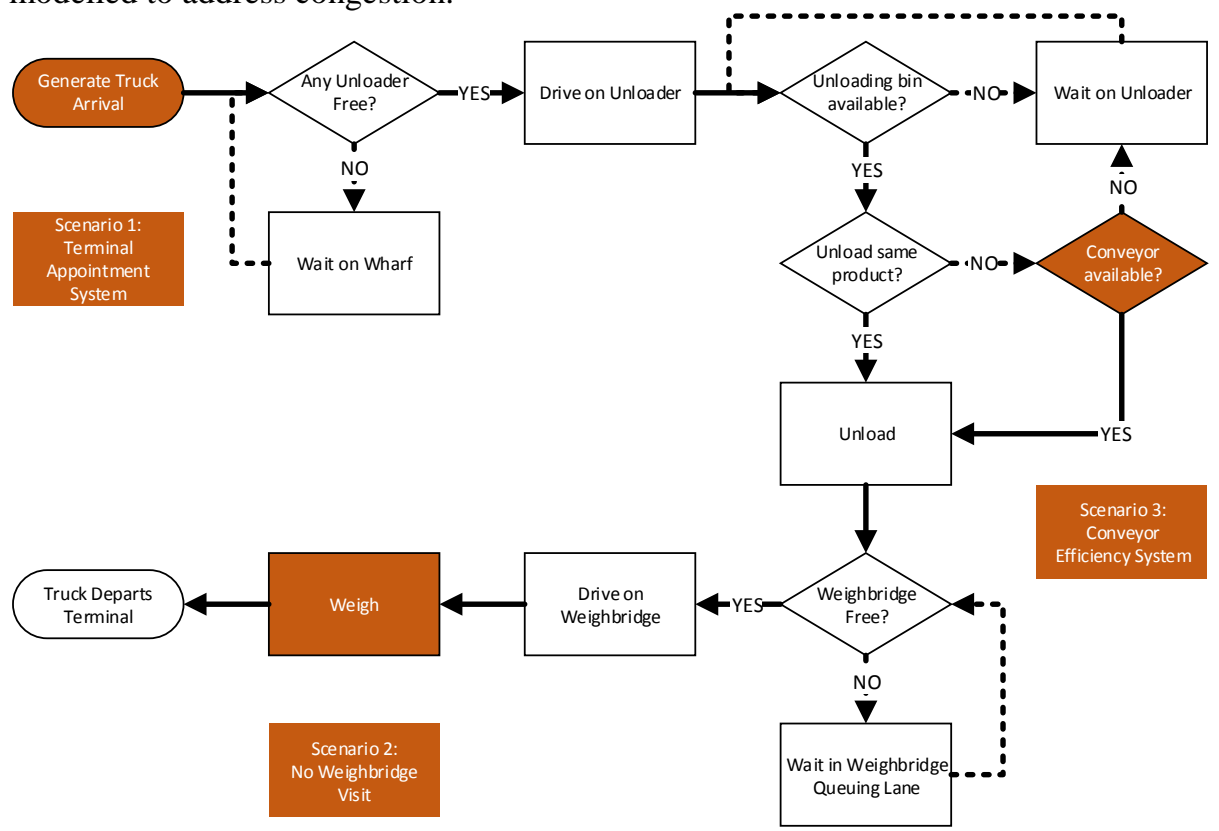

Fig. 1. Simulation model logic

The model is based on a number of assumptions drawn from observations at the terminal and the distribution fitting process:

- Two companies carry two types of products that cannot be mixed. Unloading of one product must be completed prior to unloading the other;

- Each company operates a fleet with two types of trucks in different proportions. The payloads of the two types of trucks are represented through normal distributions fitted on empirical data: $\mu_{1}=25.8, \sigma_{1}=0.798$ and $\mu_{2}=33.7, \sigma_{2}=1.82$;

- Both unloading ramps can unload both types of truck. Unloading times vary depending on the payload of the truck and are described by a lognormal distribution $(\mu=$ $5.16, \sigma=3.97)$; 
- Concurrent unloading of the same product can take place if the other unloading ramp has completed $60 \%$ of the unloading stage;

- The conveyor belt system allows a new product to be unloaded when one unloading ramp has reached $80 \%$ of the unloading stage;

- The possibility of breakdowns is not considered at this time;

- The weigh-bridge weighing in time was not included to maintain consistency with existing terminal measurements;

- The travel time between the weigh-bridge and unloading ramp and back across the weigh-bridge is considered to be fixed at 1 and 2 minutes respectively.

The inter-arrival time (IAT) is best represented by a gamma distribution $(\mathrm{k}=1.49, \theta=$ 6.97) and, the weigh-bridge weighing time on departure is described by a normal distribution $(\mu=3.46, \sigma=1.68)$.

\section{Simulation Results}

The simulation generated a base scenario and baseline terminal performance figures using the distributions fitted from empirical data which closely replicate the situation currently observed at the terminal. Three scenarios were then introduced, each representing an instantiation of a congestion management system:

- Scenario 1: implementation of a terminal appointment system (TAS) and slot truck arrivals in 10-minute intervals. Operators have some flexibility in arrivals. The deviation from the on-time arrival is described by a normal distribution $(\mu=0, \sigma=$ 2.5);

- Scenario 2: integration weigh-bridge information system and centrally storing truck tare weights and eliminate the need for trucks to empty-weigh;

- Scenario 3: reduction of conveyor operation time by 45 seconds through an improved software solution;

Table 1 provides a summary of the baseline and test scenarios. In each case, 1 year of operations was simulated with 1000 iterations per scenario. The indicators represent average results across the iterations. Except for Scenario 1, (where the inter-arrival time is changed to reflect the TAS, arrival distributions stay constant.

The most noticeable effect on the waiting and turnaround time was following the introduction of the TAS in Scenario 1. Average waiting times per truck decreased by 5.3 minutes $(76 \%)$ compared to the base scenario and turnaround times by 5.2 minutes $(23 \%)$. A similar reduction in average truck turnaround times took place in Scenario 2 (18\%), however, since the arrival times followed a similar distribution, the total waiting decreased marginally (6\%). Scenario 3 simulates the reduction by 45 seconds of the bin unloading, therefore, improvements are noticed in the cases where successive trucks carrying different products may arrive in short intervals. Average waiting times are 1.2 minutes lower (17\%) than those in the base scenario, a difference also reflected in the turnaround times with a similar absolute amount. The gain in turnaround time is a relatively modest $5 \%$. 
Table 1. Simulation scenario analysis results

\begin{tabular}{lrr}
\hline $\begin{array}{l}\text { Indicators } \\
\text { (Averages) }\end{array}$ & Base Scenario & $\begin{array}{r}\text { Scenario 1 } \\
\text { Terminal Appointment System }\end{array}$ \\
\hline Throughput (t) & $1,566,894$ & $1,563,346$ \\
Truck Visits & 52,683 & 52,559 \\
IAT (min) & 9.98 & 10 \\
Waiting/Truck (min) & $6.9(\mathrm{~m}=0, \mathrm{M}=180)$ & $1.6(\mathrm{~m}=0, \mathrm{M}=137)$ \\
Turnaround/Truck (min) & $22.2(\mathrm{~m}=7, \mathrm{M}=192)$ & $17.0(\mathrm{~m}=7, \mathrm{M}=158)$ \\
\hline Indicators & Scenario 2 & Scenario 3 \\
(Averages) & $1,566,388$ & $1,566,527$ \\
\hline Throughput (t) & 52,653 & 52,666 \\
Truck Visits & 9.98 & 9.98 \\
IAT (min) & Weigh-bridge Data Integration & Conveyor Efficiency System \\
Waiting/Truck (min) & $6.4(\mathrm{~m}=0, \mathrm{M}=143)$ & $5.7(\mathrm{~m}=0, \mathrm{M}=133)$ \\
Turnaround/Truck (min) & $18.1(\mathrm{~m}=6, \mathrm{M}=158)$ & $21.1(\mathrm{~m}=7, \mathrm{M}=143)$ \\
\hline
\end{tabular}

$*_{\mathrm{m}}=$ minimum value, $* * \mathrm{M}=$ maximum value

The simulation results show significant improvements compared to the base scenario. However, the model rests on two important assumptions. Firstly, the feasibility of the technical implementation coupled with the willingness of stakeholders to participate; secondly, that other factors outside the simulation stay unchanged. The next section discusses some implications of these assumptions.

\section{Discussion: Theory versus Practice}

Reported partial failures of implemented congestion management systems at port terminals are attributed to: limited trust between parties leading to low use [9] and system misuse [15] or abuse [7] by certain stakeholders. The unique relation between the terminal's land-side users and the terminal [13] combined with the short-term focus and drive for efficiency in the logistics industry to steer inter-organizational relationships away from trust, stability and strategic alignment [2].

With the exception of purely technical equipment improvements, successful implementations of the majority of other approaches actually rely on some information sharing between stakeholders. TAS, in particular, embeds a platform that relies on information sharing and cooperation between stakeholders for success. The behavioral changes from terminal's users are often marginalized in techno-centric implementations of TAS accentuating the gap between theory and practice. These factors influence the nature of the complex interactions at the terminal gate and highlight the need for effective strategies to aligning stakeholders' interests when addressing congestion. This should include engaging them all in the decision processes directed towards finding and developing suitable solutions. The aim of this approach is to mitigate concerns regarding system abuse, ensure that technological and business requirements of stakeholders 
are captured and facilitate the implementation process to enhance the effectiveness of the solution.

In the context of this argument, it is important to acknowledge some of the limitations regarding the simulation model presented above. The input distributions were based on approximately three months of truck visits representing a sample that may not describe the full range of interactions between the trucks and the terminal. The scope of the model was also limited to the terminal gate and the unloading equipment. Although the maritime side may operate independently of the land-side, discussions with stakeholders have already suggested that vessel arrivals are, in part, responsible for some of the arrival time fluctuations.

Future research aims to include additional scenarios in the simulation, including potential equipment and infrastructure expansion and testing the robustness of the model under changing environmental variables. Discussions with stakeholders continue as part of this research and are currently exploring perceptions of the scale of the congestion problem, the ways it may be addressed and aspects pertaining to sharing information with the terminal and with other port users. This research is part of a major ongoing research project undertaken in Australia funded by the Australian Research Council through the Industrial Transformation Research Program.

\section{Conclusion}

The land-side interface of a maritime terminal is often considered less important than the maritime side. We, however, argue sides that both are equally important. Analytically, terminal gate congestion management solutions display great potential in mitigating gate congestion. A large proportion of the literature centres on the efficiency benefits terminals can achieve and often fails to acknowledge the impact on the stakeholders affected by these systems. In practice, stakeholders seem to be rarely involved in finding and developing suitable congestion management solutions. Their business and supply chain requirements may be overlooked, which can, in some cases, lead to the lower-than-expected impact of congestion mitigation systems.

Simulation results corroborate literature findings regarding the expected impact of congestion management approaches. The TAS, as well as the weigh-bridge data integration, can reduce turnaround times by as much as 5 minutes or $23 \%$, much of it from reducing waiting times. Reducing the conveyor operation time can improve turnaround by approximately $5 \%$. The underlying challenge of achieving similar results to those achieved in simulation approaches rests upon, among other factors, the willingness of stakeholders to share information and to develop trust, stability and strategic alignment.

\section{References}

1. Bentolila, D.J. et al.: Off-peak truck deliveries at container terminals: the "Good Night" program in Israel. Marit. Bus. Rev. 1, 1, 2-20 (2016).

2. Braziotis, C., Tannock, J.: Building the extended enterprise: key collaboration factors. Int. J. Logist. Manag. 22, 3, 349-372 (2011). 
3. Bugaric, U.S. et al.: Optimal utilization of the terminal for bulk cargo unloading. Simul. Trans. Soc. Model. Simul. Int. 88, 12, 1508-1521 (2015).

4. Chen, G. et al.: Managing truck arrivals with time windows to alleviate gate congestion at container terminals. Int. J. Prod. Econ. 141, 1, 179-188 (2013).

5. Cimpeanu, R. et al.: A simulation model for the management and expansion of extended port terminal operations. Transp. Res. Part E Logist. Transp. Rev. 98, 105-131 (2017).

6. Crainic, T.G. et al.: Simulation of intermodal freight transportation systems: A taxonomy. Eur. J. Oper. Res. (2017).

7. Davies, P.: Container terminal reservation systems design and performance. In: METRANS International Urban Freight Conference Long Beach CA. pp. 1-24 (2013).

8. Dragović, B. et al.: Simulation modelling in ports and container terminals: literature overview and analysis by research field, application area and tool. Flex. Serv. Manuf. J. 29, 1, 4-34 (2017).

9. Giuliano, G., O'Brien, T.: Reducing port-related truck emissions: The terminal gate appointment system at the Ports of Los Angeles and Long Beach. Transp. Res. Part D Transp. Environ. 12, 7, 460-473 (2007).

10. Holguín-Veras, J. et al.: Overall impacts of off-hour delivery programs in New York city metropolitan area. Transp. Res. Rec. J. Transp. Res. Board. 2238, 68-76 (2011).

11. Huynh, N.: Reducing truck turn times at marine terminals with appointment scheduling. Transp. Res. Rec. J. Transp. Res. Board. 2100, 47-57 (2009).

12. Huynh, N. et al.: Truck appointment systems. Transp. Res. Rec. J. Transp. Res. Board. 2548, 1-9 (2016).

13. Jaffee, D.: Kink in the intermodal supply chain: interorganizational relations in the port economy. Transp. Plan. Technol. 39, 7, 730-746 (2016).

14. Maguire, a et al.: Relieving congestion at intermodal marine container terminals: review of tactical/operational strategies. Proc. 51st Annu. Transp. Res. Forum. 1, 631-645 (2010).

15. Morais, P., Lord, E.: Terminal appointment system study. Transp. Res. Board. 1, March, 123 (2006).

16. Munisamy, S.: Timber terminal capacity planning through queuing theory. Marit. Econ. Logist. 12, 2, 147-161 (2010).

17. Ports Australia: Trade statistics for 2014/2015.

18. van Vianen, T. et al.: Simulation-based determination of the required stockyard size for dry bulk terminals. Simul. Model. Pract. Theory. 42, 119-128 (2014).

19. Wadhwa, B.L.C.: Optimizing deployment of shiploaders at bulk export terminal. J. Waterw. Port, Coast. Ocean Eng. December, 297-304 (2000).

20. Zehendner, E., Feillet, D.: Benefits of a truck appointment system on the service quality of inland transport modes at a multimodal container terminal. Eur. J. Oper. Res. 235, 2, 461469 (2014). 